\title{
Screening of antioxidant properties from fruiting bodies, culture broth and mycelia of Ganoderma lucidum
}

\author{
Krishna Kondragunta $V^{1}$, Roshini $\mathrm{S}^{2}$ and Chandra Sekarenthiran $\mathrm{S}^{*}$

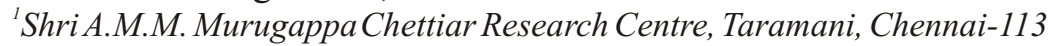 \\ ${ }^{2}$ Jeppiaar Engineering College, Chennai-119, Tamil Nadu \\ *Corresponding author Email: chandrasekarenthirans@mcrc.murugappa.org
}

(Submitted on May 27, 2020; Accepted on November 25, 2020)

\begin{abstract}
Ganoderma lucidum is a medicinal mushroom originated from China. It is also called lingzhi in China and reishi in Japan. The biologically active compounds of $G$. lucidum possess anti-cancer, anti-microbial and anti-oxidant activities. In the current study, growth of $G$. lucidum in Potato Dextrose Broth and free radical scavenging activity of mycelia, culture filtrate and fruiting bodies were examined. The maximum mycelia growth $(0.98 \pm 0.2 \mathrm{~g} / 50 \mathrm{~mL})$ was recorded on day 12 at static condition. The maximum antioxidant activity $(95.3 \pm 1.7 \%$ and $77.9 \pm 1.37 \%)$ was recorded against DPPH and ABTS radicals for Ganoderma fruiting body extract, extracted with acetone $(750 \mu \mathrm{g} / \mathrm{mL})$ and $\mathrm{methanol}(1000$ $\mu \mathrm{g} / \mathrm{mL}$ concentration). Static condition recorded the maximum activity $(35.79 \pm 8.5 \%)$ on day 9 for culture filtrate against DPPH whereas $3^{\text {rd }}$ day recorded the maximum $(48.7 \pm 1.6 \%)$ activity against $A B T S$ assay. The maximum activity $(51.24 \pm 7.8 \%)$ recorded for the mycelia harvested on day 12 against DPPH and $(62.28 \pm 8.2 \%)$ against $A B T S$ radical.
\end{abstract}

KEYWORDS: Ganoderma lucidum, antioxidant, radical scavenging activity, DPPH, ABTS

\section{INTRODUCTION}

Ganoderma lucidum, a woody mushroom species belonging to the family Ganodermataceae of class Agaricomycetes (Wu et al., 2016, Wu et al., 2019), is used as dietary supplement in the Eastern part of the world for many years with no toxic effect reported (Eo et al., 1999; Liu et al., 2002). It is considered as a health tonic for promoting health and longevity (Wang et al., 2017).

G. lucidum is known for its bioactive compounds, therapeutic and anti-ageing properties and promotion of health (Wasser, 2005). There are many reports on the therapeutic properties of G. lucidum like antioxidant, anti-inflammatory, anticancer, immunomodulatory, anti-microbial and anti-diabetic activities (Gao et al., 2002, 2003; Halpern, 2007; Dudhgaonkar et al., 2009; Li et al., 2015; Liu et al., 2015; Ma et al., 2015; Pan et al., 2015; Chiu et al., 2017; Wang et al., 2017; Zheng and Chen, 2017; Yang et al., 2018).

The major chemical constituents of $G$. lucidum like polysaccharides, triterpenes, sterols, lectins and some proteins are reported to have beneficial properties in the prevention and treatment of a variety of ailments. It is interesting that more than 150 triterpenes and 50 carcinostatic polysaccharides were identified from this mushroom during the last three decades (Fang and Zhong, 2002; Leung et al., 2002; Klaus and Niksic, 2007).

The process of oxidation in living organisms is essential for production of energy. But during this process, oxidants and free radicals are produced which is a physiologic phenomenon in cells. The imbalance between the oxidants and antioxidants is reported to cause the oxidative stress (Sies, 2000; Ahmed, 2005). This oxidative stress leads to pathophysiological states such as neurodegeneration, cancer, cardiovascular diseases, mutagenesis and aging (Pham-Huy et al., 2008; Kabel, 2014). Antioxidants are reported to scavenge the reactive oxidizing species (Chapple, 1997; Packer and Cedenas, 2007).

The antioxidant potential of G. lucidum was studied by many researchers using different methods like DPPH radical scavenging activity, hydrogen peroxide radical scavenging activity, superoxide radical scavenging activity, ABTS radical scavenging activity, metal chelating ability, reducing power, lipid peroxidation assay, total antioxidant capacity, FRAP and ORAC (Baskar et al., 2008; Joseph et al., 2009; Kamra and Bhatt, 2012; Samarakoon et al., 2013; Hasnat et al., 2013; Lin et al., 2015; Cör et al., 2017: Dong et al., 2019).

The antioxidant activity of the extracts from mycelia of $G$. lucidum as well as culture filtrate was determined against DPPH and ABTS by growing G. lucidum in Potato Dextrose Broth (PDB) incubated under static and rotary shaking conditions for 15 days. The mycelium obtained from the PDB and the organically cultivated G. lucidum fruiting body at MCRC was extracted with different solvents in two different conditions such as hot and $30^{\circ} \mathrm{C}$ and used for the study.

\section{MATERIALS AND METHODS}

Culturing in PDB: Pure culture of G. lucidum available at the culture collection of Shri A M M Murugappa Chettiar Research Centre, Taramani, Chennai was used in this study. Seven days old $8 \mathrm{~mm}$ sized mycelia disc of G. lucidum was used for inoculating PDB and the inoculated broth was incubated under static $\left(28 \pm 2^{\circ} \mathrm{C}\right)$ and shaking $\left(28 \pm 2^{\circ} \mathrm{C}\right.$ and $\left.120 \mathrm{rpm}\right)$ conditions. The mycelia was harvested from the broth at regular intervals of 3, 6, 9, 12 and 15 days. The harvested mycelium and culture filtrate samples were analyzed for their antioxidant activity.

Preparation of crude extract from fruit body and mycelium: Organically cultivated Ganoderma fruit body was available at Shri A M M Murugappa Chettiar Research Centre, Taramani, Chennai. The extraction of compounds from the fruiting bodies was carried out using different solvents (Ethanol, Methanol, Ethyl acetate and Acetone) under rotary shaking $\left(120 \mathrm{rpm}, 37^{\circ} \mathrm{C}\right)$ condition following the modified procedure of Veljovic et al. (2017) and hot extraction condition by refluxing method ( $5 \mathrm{hrs})$, the modified procedure of Cör et al. (2017). Extracts were transferred to crucible, evaporated at 32 $\pm 2^{\circ} \mathrm{C}$ and yield was recorded. Extracts were re-dissolved and 
used for quantifying the antioxidant activity.

Acetone was used for the extraction of bioactive compounds from the mycelium. For this purpose Acetone was added to harvested G. lucidum mycelia (200 mg) in different days (3$15)$ and extraction done by keeping the mixture in water bath at $50^{\circ} \mathrm{C}$ for $6 \mathrm{hrs}$. The filtered extracts were kept for drying under room temperature $\left(32 \pm 2^{\circ} \mathrm{C}\right)$. Dried sample was taken for antioxidant activity studies.

Antioxidant activity assays: The G. lucidum fruit body extracts (obtained through Soxhlet and rotary process), mycelial extract and the culture filtrate (broth after removing the mycelium) were tested for their antioxidant potential against DPPH and ABTS radical scavenging activity. Investigations for DPPH radical scavenging activity of mycelial samples were carried out for the samples obtained after $6^{\text {th }}$ day onwards since the mycelial sample obtained on the $3^{\text {rd }}$ day was less.

DPPH (1,1-diphenyl-2-picrylhydrazyl) radical scavenging activity: DPPH (3.98 $\mathrm{mg}$ ) was dissolved in 50 $\mathrm{mL}$ of methanol and this served as stock of DPPH solution ( $0.1 \mathrm{mM}$ concentration). The scavenging activity for DPPH free radicals was measured according to Zhao et al. (2006). For this purpose to $2 \mathrm{~mL}$ of $0.1 \mathrm{mM}$ DPPH, $1 \mathrm{~mL}$ of sample (extracts from different extraction methods) at different concentrations $(250,500,750$ and $1000 \mu \mathrm{g} / \mathrm{mL}$ concentrations) was added individually. The mixture was shaken vigorously and allowed to reach a steady state at room temperature for $30 \mathrm{~min}$. Decolourization of DPPH was determined by measuring the decrease in absorbance at 517 $\mathrm{nm}$, and the DPPH radical scavenging effect was calculated according to the following equation:

$$
\% \text { scavenging activity }=[(\mathrm{A} 0-\mathrm{A} 1) / \mathrm{A} 0] \times 100
$$

Where

A0 represents the absorbance of DPPH without sample solution.

A1 represents the absorbance of DPPH with sample

ABTS (2,2'-azino-bis(3-ethylbenzothiazoline-6-sulfonic acid) radical scavenging activity: Scavenging activity of ABTS radical was carried out following the procedure given by Mahendran et al. (2012). For this purpose $7 \mathrm{mM}$ ABTS solution was prepared by adding ABTS (36 mg of ABTS in distilled water) to a solution of potassium per sulphate (189 $\mathrm{mg}$ in distilled water). To this $5 \mathrm{~mL}$ of ABTS and $144 \mu \mathrm{L}$ potassium persulfate was added and kept overnight to activate the radicals. Absorbance of ABTS was adjusted to $0.7 \mathrm{OD}$ at $734 \mathrm{~nm}$ wavelengths and it served as ABTS solution. The antioxidant activity of the samples $(250,500,750$ and 1000 $\mu \mathrm{g} / \mathrm{mL}$ concentrations) was studied by the following standard method. For this purpose $3 \mathrm{~mL}$ of ABTS solution was taken in test tube to which $60 \mu \mathrm{L}$ of sample was added and mixed vigorously for 20 minutes. The absorption was read at 734 $\mathrm{nm}$. The scavenging activity of the samples was calculated by using following formula.

$$
\% \text { scavenging rate }=[(\mathrm{A} 0-\mathrm{A} 1) / \mathrm{A} 0] \times 100
$$

Where

A0 represents the absorbance of control.

A1 represents the absorbance of ABTS with sample

\section{RESULTS}

Growth studies of $\boldsymbol{G}$. lucidum: The maximum mycelia yield of $0.98 \pm 0.2 \mathrm{~g}$ and $0.62 \pm 0.3 \mathrm{~g} / 50 \mathrm{~mL}$ (dry weight) was obtained in PDB on $12^{\text {th }}$ day under static and shaking conditions, respectively. The study shows that the mycelia growth declined after the $12^{\text {th }}$ day under both the incubation conditions (Fig. 1). Static condition took little longer time initially to show the notable growth compared to the shaking condition.

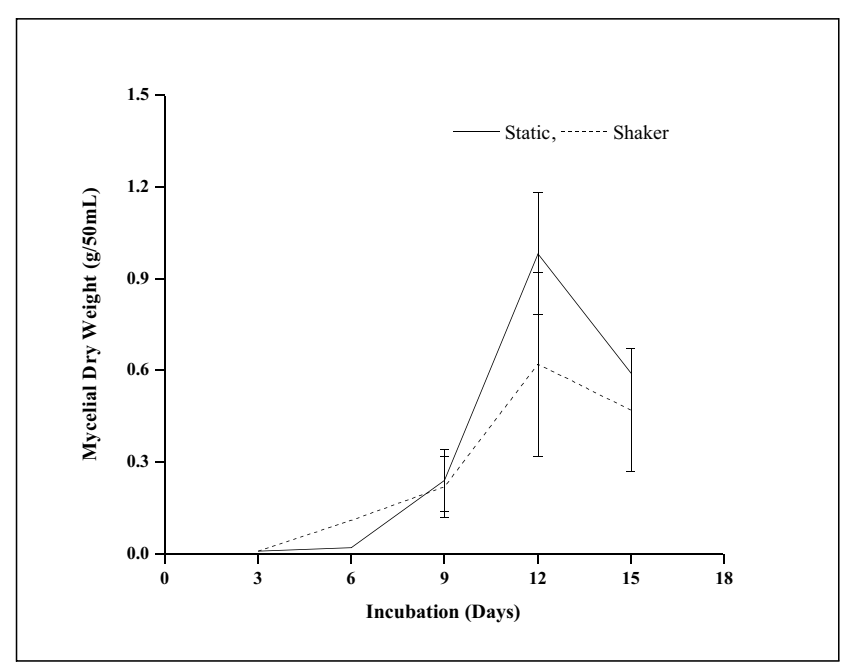

Fig. 1 Growth of G. lucidum in PDB

Crude extract from $\boldsymbol{G}$. lucidum: The data given in table 1 provides the results of the yield of crude extract obtained from different solvent extractions under two different extraction conditions. The maximum yield $(160 \mathrm{mg} / 2 \mathrm{~g})$ of the extracted compounds was observed in Ethyl acetate extract and 80 $\mathrm{mg} / 2 \mathrm{~g}$ was obtained in ethanol extract using soxhlet process.

The maximum crude extract obtained through shaking process was $70 \mathrm{mg} / 2 \mathrm{~g}$ in ethanol extract.

Table 1: Yield of G. lucidum extracts, extracted with different solvents

\begin{tabular}{|c|c|c|}
\hline \multicolumn{3}{|c|}{ Yield (mg / 2g) } \\
\hline Solvent & Rotary shaker & Soxhlet \\
\hline Methanol & 40 & 60 \\
\hline Ethanol & $\mathbf{7 0}$ & 80 \\
\hline Acetone & 50 & 30 \\
\hline Ethyl acetate & 40 & $\mathbf{1 6 0}$ \\
\hline
\end{tabular}

DPPH radical scavenging activity for different solvent extracts of $\boldsymbol{G}$. lucidum fruiting body: In DPPH radical scavenging activity, G. lucidum fruiting body extracts recorded maximum activity $(95.3 \pm 1.7 \%)$ for acetone extract extracted under shaking condition, followed by methanol extract $(94.27 \pm 0.3 \%)$ extracted through soxhlet method (Fig. 2a). An increasing trend in antioxidant activity was observed for acetone extracts under both the conditions. Ethyl acetate extract, extracted by shaking condition have shown DPPH radical scavenging activity but there was no activity for the extracts obtained through soxhlet process in any of the 
concentrations tested. Likewise, the extracts obtained using ethanol under both the conditions didn't show any activity for DPPH. The maximum activity for ethyl acetate extract recorded was $70.31 \pm 5.4 \%$ at $500 \mu \mathrm{g} / \mathrm{mL}$ concentration.

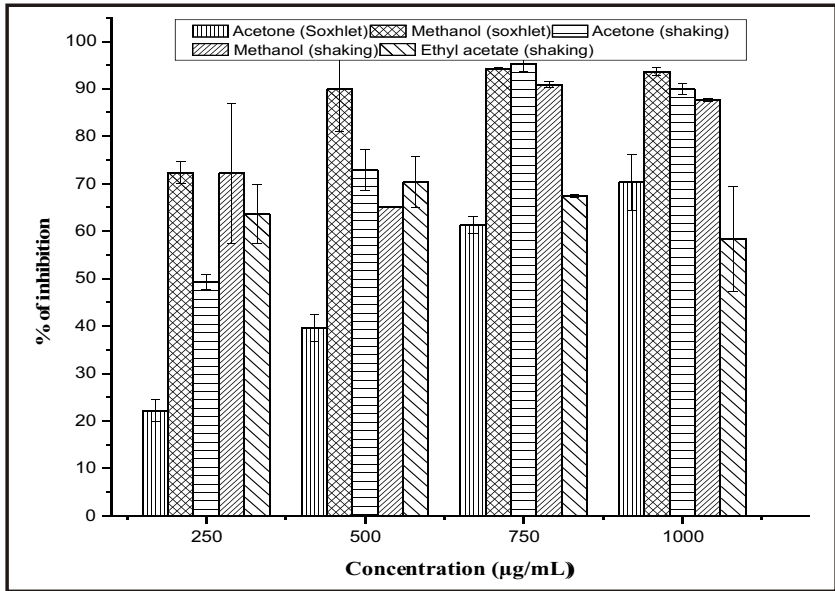

Fig. 2a: DPPH radical scavenging activity of G. lucidum extracted with different solvents

ABTS radical scavenging activity for different solvent extracts of $\boldsymbol{G}$. lucidum fruiting body: The results of ABTS radical scavenging activity is depicted in Fig. 2b. Maximum activity $(77.9 \pm 1.37 \%)$ was recorded at $1000 \mu \mathrm{g} / \mathrm{mL}$ concentration for the methanol extract, extracted under the shaking condition. Minimum scavenging activity $(14.12 \pm 8.07 \%)$ against the ABTS radicals was recorded for the Methanol extract at $250 \mu \mathrm{g} / \mathrm{mL}$ concentration. Extraction done under shaking condition gave better results in comparison to the extraction done using soxhlet extraction method. Ethanol extract gave least activity under both the conditions of extractions.

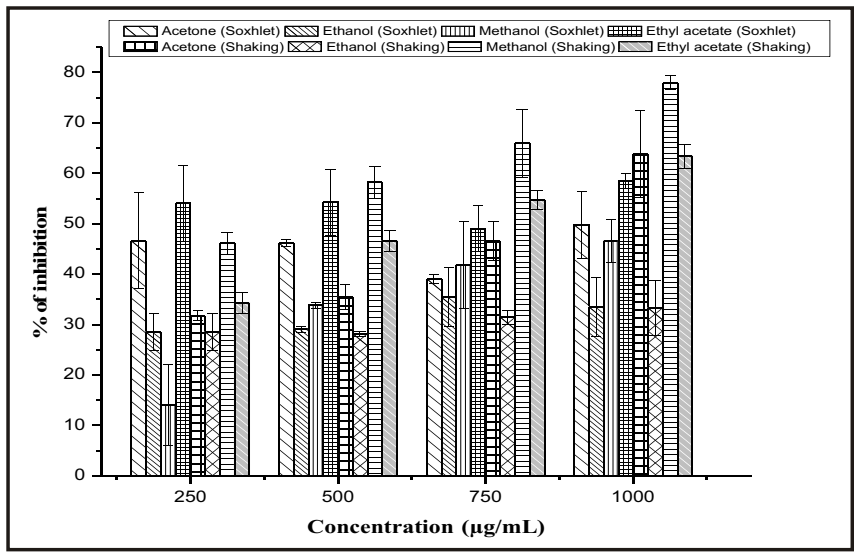

Fig. 2b ABTS radical scavenging activity of G. lucidum extracted with different solvents

DPPH radical scavenging activity for broth samples of $G$. lucidum: The results of DPPH radical scavenging activity of culture filtrate samples is depicted in Fig. 3a. Maximum activity $(35.79 \pm 8.5 \%)$ was recorded for the culture filtrate obtained from 9 day old culture incubated under static condition, followed by $34.4 \pm 16.3 \%$ incubated under shaking condition on day 9 .

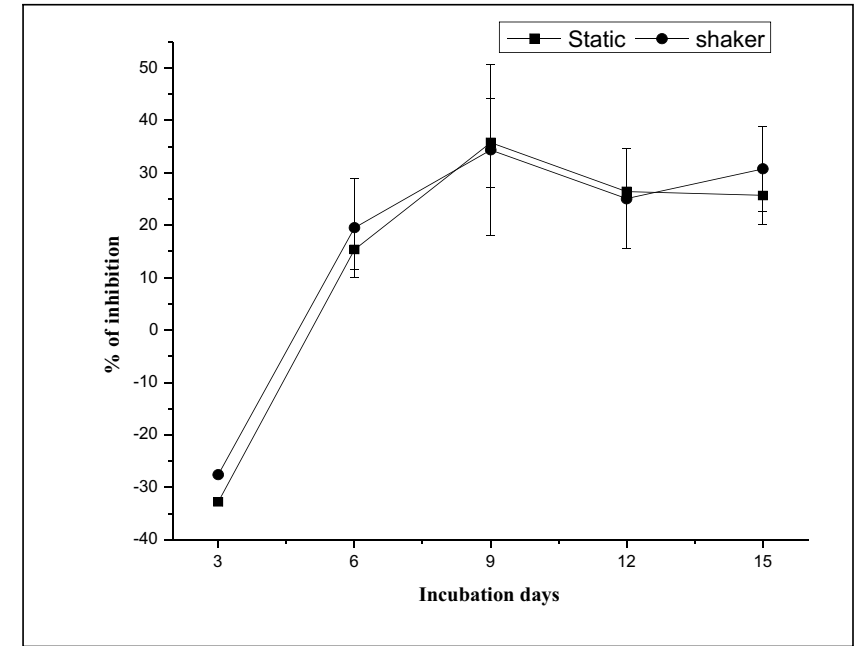

Fig. 3a. DPPH radical scavenging activity of culture filtrate sample

ABTS radical scavenging activity for broth samples of $\boldsymbol{G}$. lucidum: The results of ABTS radical scavenging activity of culture filtrate is represented in Fig. 3b. Maximum activity was recorded for the culture filtrate samples obtained from 3 day old culture kept under both the conditions. No significant variation was observed in the results obtained under static and shaking conditions on day 3 .

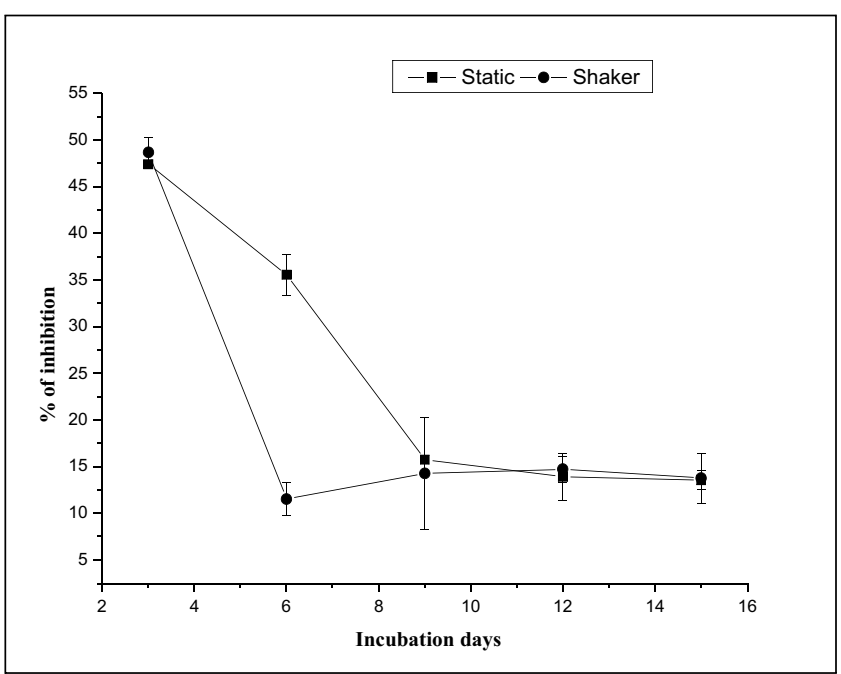

Fig. 3b. ABTS radical scavenging activity of culture filtrate

DPPH radical scavenging activity for mycelia samples of G. lucidum: The result of DPPH radical scavenging activity of mycelial extracts are depicted in the following graphic presentation (Fig. 4a).

The maximum activity $(51.24 \pm 7.8 \%)$ was recorded for mycelia grown under shaking condition on the $12^{\text {th }}$ day whereas the extracts obtained through static conditions have shown maximum activity on the $15^{\text {th }}$ day $(43.5 \pm 1.5 \%)$. Samples incubated under shaking conditions gave the better activity compared to the sample incubated under static conditions. 


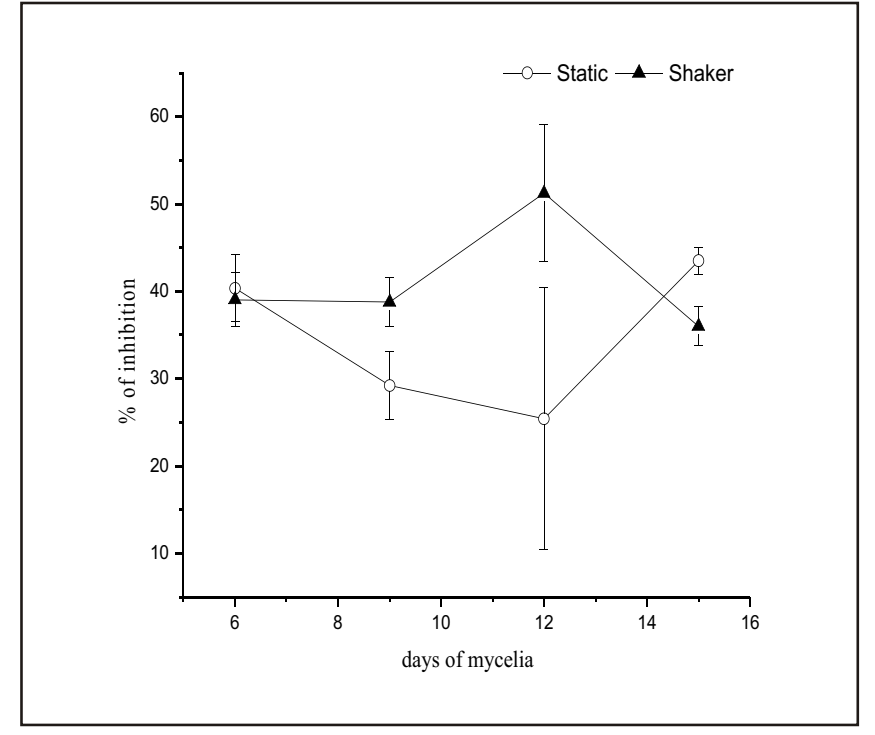

Fig. 4a. DPPH radical scavenging activity of different day's mycelium

ABTS radical scavenging activity for mycelia of $G$. lucidum: The maximum ABTS radical scavenging activity $(62.28 \pm 8.2 \%)$ was recorded on day 15 under static condition. Minimum activity was recorded on the $9^{\text {th }}$ day mycelia $(17.04 \pm 3.9 \%)$ and $(12.36 \pm 0.21 \%)$ under both static and shaking conditions, respectively. Better scavenging activity was obtained under static condition as compared to the shaking condition (Fig. 4b).

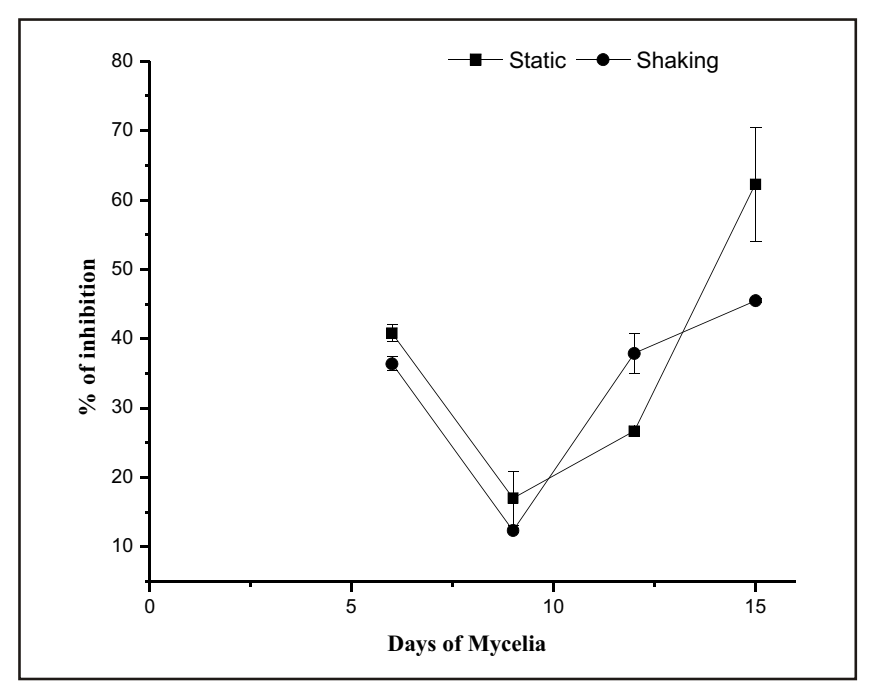

Fig. 4b. ABTS radical scavenging activity of different days of mycelium

\section{DISCUSSION}

The present investigation is exclusively focused on the screening of antioxidant properties of mycelium and culture filtrate harvested on different day's time interval and its comparison with the antioxidant activity of the fruiting body. On the basis of the results obtained it can be concluded that crude extract of fruiting body exhibited better activity against both DPPH and ABTS radicals in comparison to mycelia and culture broth. Maximum activity $(95.3 \pm 1.7 \%$ and $77.9 \pm 1.3$
\%) was recorded by fruiting body against DPPH and ABTS radicals, respectively. In culture broth samples maximum activity $(35.79 \pm 8.5 \%)$ was there on $9^{\text {th }}$ day when incubated under static condition against DPPH and $48.7 \pm 1.6 \%$ on $3^{\text {rd }}$ day when incubated under shaking condition against ABTS radical. Mycelia harvested on day 12 recorded the maximum activity $(51.24 \pm 7.8 \%)$ against DPPH radical extracted under shaking condition and $62.28 \pm 8.2 \%$ against ABTS radical extracted under static condition.

The available literatures show that the crude extracts of $G$. lucidum prepared using water as well as organic solvents exhibited antioxidant activities. Agarwal et al. (2012) reported better activity for crude extract of G. lucidum, extracted with hot water compared to hydro alcoholic, chloroform and petroleum ether extracts. It was reported that hot water extract recorded the maximum activity for both $\mathrm{DPPH}(>90 \%)$ and ABTS $(>80 \%)$ radical scavenging activity at $500 \mu \mathrm{g} / \mathrm{mL}$ concentration. During the present investigations crude extract of $G$. lucidum fruiting body, extracted with acetone recorded the maximum activity $(95.3 \pm 1.7 \%)$ at $750 \mu \mathrm{g} / \mathrm{mL}$ concentration. The results obtained by Kalyoncu et al. (2010) corroborated with similar such results obtained by Agarwal et al. (2012) who documented better scavenging activity of crude water extract of G. lucidum against DPPH (21.5\%) and ABTS (70.71\%) at $1 \mathrm{mg} / \mathrm{mL}$ concentration. On the other hand, Stajkovic et al. (2014) compared the DPPH free radical scavenging activity of two fruiting bodies collected from Serbia and China and reported 0.17 and $0.13 \mathrm{~g} / \mathrm{mL} \mathrm{IC}_{50}$, respectively for methanol extracts. Presently in the methanol extract more than $70 \%$ activity was recorded at $250 \mu \mathrm{g} / \mathrm{mL}$ concentration, extracted under both the conditions. Likewise, Samarakoon et al. (2013) also reported the antioxidant activity of $2.09 \mathrm{mg} / \mathrm{mL}$ $\mathrm{IC}_{50}$ for ethyl acetate extract of $G$. lucidum fruiting body and $1.1 \mathrm{mg} / \mathrm{mL} \mathrm{IC}_{50}$ for methanol extract. In the present study Ethyl acetate extract exhibited $63 \%$ activity at $250 \mu \mathrm{g} / \mathrm{mL}$ concentration whereas methanol extract recorded $>90 \%$ activity at $750 \mu \mathrm{g} / \mathrm{mL}$ concentration. Cör et al. (2017) reported maximum inhibition of DPPH radicals for $G$. lucidum fruiting body extract when hot acetone solvent was used, followed by hot ethanol, methanol, water and hexane extracts. The antioxidant activity of $0.48 \%-23.66 \%$ was obtained using DPPH free radical scavenging method with fruiting body extract.

The antioxidant activity of $35 \%$ was recorded during the present study using culture filtrate $(\mathrm{PDB})$ on $9^{\text {th }}$ day which is in conformity with the similar results presented by Cilerdzic et al. (2016). In the culture broth studied by these authors for antioxidant activity it was reported that culture maintained in malt dextrose medium (MDM), incubated for 21 days, recorded maximum activity (39.6\%) with $100 \%$ broth (MDM) concentration (Cilerdzic et al., 2016). As compared the number of days to obtain the activity was reduced during the present investigations.

While working with the mycelia extract, it was observed that 11 days old mycelia extracted with culture broth exhibited $70 \%$ scavenging activity at $0.5 \mathrm{mg} / \mathrm{mL}$ concentration whereas Asatiani et al. (2007) reported that the residue extracted with 
ethanol resulted in $77 \%$ scavenging activity at $1.5 \mathrm{mg} / \mathrm{mL}$ concentration. Likewise, Darsih et al. (2019) also reported that the scavenging of DPPH radical by methanol extract of mycelia cultivated on PDB $(22.140 \pm 3.25 \%)$ was higher than obtained in the mycelia cultured on sweet corn media $(12.840 \pm 2.03 \%)$ at $0.2 \mathrm{mg} / \mathrm{mL}$.

It was shown by Yan et al. (2019), that the GLP (G. lucidum polysaccharide) in the G. lucidum fruit body extract exhibited strong antioxidant effects, including scavenging of DPPH• and $\mathrm{HO} \bullet$, with IC50 values of $0.55 \mathrm{mg} / \mathrm{mL}$ and $0.76 \mathrm{mg} / \mathrm{mL}$, respectively. In another report by Mahendran et al. (2012), it was reported that crude EPS exhibited higher DPPH radical scavenging activity. Heleno et al. (2012) extracted phenolic compounds and polysaccharides from mycelia and fruiting bodies, and spores of G. lucidum; and reported that polyphenols extracted from mycelia and fruiting bodies showed the better scavenging activity than the polysaccharides against the DPPH and reducing power assay but the results were vice versa in spores. The phenolic extract of mycelia grown in solid MMN media recorded $\mathrm{IC}_{50}$ at 0.9 $\mathrm{mg} / \mathrm{mL}$ concentration whereas phenolic extract of mycelia grown in liquid MMN (Melin Norkans media) media recorded $1.32 \mathrm{mg} / \mathrm{mL} \mathrm{IC}_{50}$ value. Tan et al. (2018) reported $65-68 \%$ radical scavenging activity against DPPH radicals for polysaccharides produced under the heat stress from the G. lucidum. Presently free radical scavenging activity was reported for fruiting body powder, mycelia and culture broth of G. lucidum grown for different days. The outcome of the experiment is encouraging and further studies in cost effective medium will provide path for preparing mushrooms as food supplements.

\section{CONCLUSION}

In the present study, the maximum antioxidant activity was observed in G. lucidum fruiting body. The culture filtrate as well as mycelia has also shown antioxidant activity although it is not at par with the activity obtained from the extract prepared using fruit bodies. The crude EPS of the fruiting body of G. lucidum, mycelium and exopolysaccharides in the culture filtrate might have induced the antioxidant activity as reported in several other reports. Further optimization studies are required to produce nutrient rich mycelium. The potent antioxidant activity of G. lucidum mushroom indicates the beneficial effects of mushroom. The report by Celal, (2019) stated that G. lucidum is a natural antioxidant source which can be consumed.

\section{ACKNOWLEDGEMENTS}

The authors would like to express their gratitude to Shri A M M Murugappa Chettiar Research Centre for providing laboratory facility to carry out the present work. Thanks are also due to Dr. K. K. Sharma (Chief Scientist), Dr. N. Unnamalai (Principal Scientist) and Dr. Maya Subramoni (Senior Principal Scientist) for their supervision and constant support during the study.

\section{REFERENCES}

Agarwal, K., Chakarborthy, G.S. and Verma, S. 2012. In vitro antioxidant activity of different extracts of
Ganoderma lucidum. DHR Int. J. Pharm. Sci. Res. 3: $2278-8328$.

Ahmed, R.G. 2005. Is there a balance between oxidative stress and antioxidant defense system during development?. Med. J. Islamic Academy of Sci. 15(2): 55-63.

Asatiani, M.D., Elisashvili, V.I., Wasser, S.P., Reznick, A.Z. and Nevo, E. 2007. Free- radical scavenging activity of submerged mycelium extracts from higher basidiomycetes mushrooms.Biosci. Biotechnol. Biochem. 71:3090-3092.

Baskar, R., Lavanya, R., Mayilvizhi, S. and Rajasekaran, P. 2008. Free radical scavenging activity of antitumour polysaccharide fractions isolated from Ganoderma lucidum (Fr.) P. Karst. Natural Product Radiance. 7(4): 320-325.

Celal, B. 2019. Antioxidant and antimicrobial capacities of Ganoderma lucidum. Journal of Bacteriology \& Mycology: Open Access. 7(1):5-7.

Chapple, I.L.C. 1997. Reactive oxygen species and antioxidants in inflammatory diseases. J. Clin. Periodontol. 24: 287-296.

Chiu, H.F., Fu, H.Y., Lu, Y.Y., Han, Y.C., Shen, Y.C., Venkatakrishnan, K., Golovinskaia, O. and Wang, C.K. 2017. Triterpenoids and polysaccharide peptides-enriched Ganoderma lucidum: a randomized, double-blind placebo-controlled crossover study of its antioxidation and hepatoprotective efficacy in healthy volunteers. Pharm. Biol 55(1):1041-1046.

Cilerdzic, J., Kosanic, M., Stajic, M., Vukojevic, J. and Rankovic, B. 2016. Species of genus Gan oder m a (Agaricomycetes) fermentation broth: a novel antioxidant and antimicrobial agent. Int. J. Med. Mushrooms 18: 397-404

Cör, D., Botic, T., Gregori, A., Pohleven, F. and Knez, Ž. 2017. The effects of different solvents on bioactive metabolites and "in vitro" antioxidant and antiacetylcholinesterase activity of Ganoderma lucidum fruiting body and primordia extracts. Maced. J. Chem. Chem. Eng. 36(1): 129-141.

Darsih, C., Indrianingsih, A.W., Apriyana, W., Hayati, S.N., Rosyida, V.T., Nisa, K., Ratih, D. and Indirayati, N. 2019. Antioxidant activity of methanol extracts from Ganoderma lucidum Karst. Mycelia. Earth Environ. Sci. 251:012015

Dong, Q., He, D., Ni, X., Zhou, H. and Yang, H. 2019. Comparative study on phenolic compounds, triterpenoids, and antioxidant activity of Ganoderma lucidum affected by different drying methods. J. Food Meas. Charact. 13(4):3198-3205.

Dudhgaonkar, S., Thyagarajan, A. and Sliva, D. 2009. Suppression of the inflammatory response by 
triterpenes isolated from the mushroom Ganoderma lucidum. Int. Immunopharmacol 9(11):1272-1280.

Eo, S.K., Kim, Y.S., Lee, C.K. and Han, S.S. 1999. Antiherpetic activities of various protein bound polysaccharides isolated from Ganoderma lucidum.J. Ethnopharmacol.68(13):175-181

Fang, Q.H.and Zhong, J.J. 2002. Effect of initial pH on production of ganoderic acid and polysaccharide by submerged fermentation of Ganoderma lucidum. Process Biochem. 37: 769-774

Gao, Y. H., Zhou, S.F., Chen, G.L., Dai, X.H. and Ye, J.X. 2002. A phase I/II study of a Ganoderma lucidum (Curr.: Fr.) P. Karst. Extract (Ganopoly) in patients with advanced cancer. Int. J. Med. Mushrooms 4: 207-14.

Gao, Y.H., Zhou, S.F., Jiang, W.Q., Huang, M. and Sai, X.H. 2003. Effects of Ganopoly (a Ganoderma lucidum polysaccharide extract) on immune functions in advanced-stage cancer patients. Immunol. Invest. 32: $201-15$

Halpern, G.M. 2007. Healing mushrooms. Square One Publishers, Inc

Hasnat, M., Pervin, M. and Lim, B.O. 2013. Acetylcholinesterase inhibition and in vitro and in vivo antioxidant activities of Ganoderma lucidum grown on germinated brown rice. Molecules 18(6): 6663 6678 .

Heleno, S.A., Barros, L., Martins, A., Queiroz, M.J.R., Santos-Buelga, C.and Ferreira, I.C. 2012. Fruiting body, spores and in vitro produced mycelium of Ganoderma lucidum from Northeast Portugal: A comparative study of the antioxidant potential of phenolic and polysaccharidic extracts. Food Res. Int. 46:135-140.

Joseph, S., Sabulal, B., George, V., Smina, T.P. and Janardhanan, K.K. 2009. Antioxidative and antiinflammatory activities of the chloroform extract of Ganoderma lucidum found in South India. Scientia pharmaceutica 77(1):111-122.

Kabel, A.M. 2014. Free radicals and antioxidants: role of enzymes and nutrition. World Journal of Nutrition and Health 2:35-38.

Kalyoncu, F., Oskay, M. and Kayalar, H. 2010. Antioxidant activity of the mycelium of 21 wild $\mathrm{m} \mathrm{u} \mathrm{s} \mathrm{h} \mathrm{r} \mathrm{o} \mathrm{o} \mathrm{m}$ species. Mycology 1:195-199.

Kamra, A. and Bhatt, A.B. 2012. Evaluation of antimicrobial and antioxidant activity of Ganoderma lucidum extracts against human pathogenic bacteria. Int. J. Pharm. Res. Sci. 4(2):359-362.

Klaus, A. and Niksic, M. 2007. Influence of the extracts isolated from Ganoderma lucidum mushroom on some microorganisms. Zbornik Maticesrpskezaprirodnenauke 113: 26
Leung, S.W., Yeung, K., Ricky, Y.S. and Man Y. 2002. Lingzhi (Ganoderma) research-the past, present and future perspectives. In: Ganoderma: Genetics, Chemistry, Pharmacology and Therapeutics - Proceedings of International Symposium on Ganoderma Research.

Li, A., Shuai, X., Jia, Z., Li, H., Liang, X., Su, D. and Guo, W. 2015. Ganoderma lucidum polysaccharide extract inhibits hepatocellular carcinoma growth by down regulating regulatory $\mathrm{T}$ cells accumulation and function by inducing microRNA-125b. J. Transl. Med. 13 (1): 100 .

Lin, M., Yu, Z., Wang, B., Wang, C.C., Weng, Y.M. and Koo. M. 2015. Bioactive constituent characterization and antioxidant activity of Ganoderma lucidum extract fractionated by supercritical carbon dioxide. Sains Malays 44 (12):1685-1691.

Liu, C., Dunkin, D., Lai, J., Song, Y., Ceballos, C., Benkov, K. and Li, X.M. 2015. Anti-inflammatory effects of Ganoderma lucidum triterpenoid in human crohn's disease associated with down regulation of NF-kB signaling. Inflamm Bowel Dis. 21(8):1918-1925.

Liu, X., Yuan, J.P., Chung, C.K. and Chen, X.J. 2002. Antitumor activity of the sporoderm broken germinating spores of Ganoderma lucidum. Cancer lett. 182: 155-161.

Ma, H.T., Hsieh, J.F. and Chen, S.T. 2015. Anti-diabetic effects of Ganoderma lucidum. Phytochemistry 114: 109-113.

Mahendran, S., Anandapandian, K.T.K., Shankar, T., Chellaram, C. and Vijayabaskar, P. 2012. Antioxidant properties of Ganoderma lucidum crude exopolysaccharide. Indian J. Innov. Dev. 1: 1-6.

Packer, L. and Cadenas, E. 2007. Oxidants and antioxidants revisited new concepts of oxidative stress. Free Radic. Res. 41: 951-952.

Pan, D., Wang, L., Chen, C., Hu, B. and Zhou, P. 2015. Isolation and characterization of a hyper branched proteoglycan from Ganoderma lucidum for antidiabetes. Carbohydrate polymers 117:106-114.

Pham-Huy, L.A., He, H.and Pham-Huy, C. 2008. Free radicals, antioxidants in disease and health. Int. J. Biomed. Sci. 4: 89.

Samarakoon, K.W., Lee, J.H., De Silva, E.D., Kim, E.A., Wijesundara, R.L., Lakmal, H.C. and Jeon, Y.J. 2013. Bioactivity evaluation of organic solvent extractions of Ganoderma lucidum: a Sri Lankan basidiomycete. JNSF 41 (3):249-57 
Sies, H. 2000. What is oxidative stress?. In: Oxidative stress and vascular disease (pp. 1-8). Springer, Boston, MA.

Stojkovic, D.S., Barros, L., Calhelha, R.C., Glamoclija, J., Ciric, A., Van Griensven, L.J., Sokovic, M. and Ferreira, I. 2014. A detailed comparative study between chemical and bioactive properties of Ganoderma lucidum from different origins. Int. J. Food Sci. Nutr. 65: 42-47.

Tan, X., Sun, J., Xu, Z., Li, H., Hu, J., Ning, H., Qin, Z., Pei, H., Sun, T. and Zhang, X. 2018. Effect of heat stress on production and in-vitro antioxidant activity of polysaccharides in Ganoderma lucidum. Bioproc. biosyst. eng. 41: 135-141.

Veljovic, S., Veljovic, M., Nikicevic, N., Despotovic, S., Radulovic, S., Nikšic, M. and Filipovic, L. 2017. Chemical composition, antiproliferative and antioxidant activity of differently processed Ganoderma lucidum ethanol extracts. J. Food Sci. Technol. 54: 1312-1320.

Wang, Y., Liu, Y., Yu, H., Zhou, S., Zhang, Z., Wu, D., Yan, M., Tang, Q. and Zhang, J. 2017. Structural characterization and immuno-enhancing activity of a highly branched water-soluble $\beta$-glucan from the spores of Ganoderma lucidum. Carbohydrate polymers 167: 337-344.

Wasser, S.P. 2005. Reishi or ling zhi (Ganoderma lucidum). Encyclopedia of dietary supplements 1: 603-622.

Wu, H., Tang, S., Huang, Z., Zhou, Q., Zhang, P. and Chen, Z. 2016. Hepatoprotective effects and mechanisms of action of triterpenoids from lingzhi or reishi medicinal mushroom Ganoderma lucidum (Agaricomycetes) on $\alpha$-amanitin-induced liver injury in mice. Int. J. Med. Mushrooms 18 (9): 841 850

Wu, Q., Li, Y., Peng, K., Wang, X.L., Ding, Z., Liu, L., Xu, P. and Liu, G.Q. 2019. Isolation and Characterization of Three Antihypertension Peptides from the Mycelia of Ganoderma lucidum (Agaricomycetes). J. Agric. Food Chem. 67 (29): 8149-8159.

Yan, Z., Li,S., Yu, H. and Xin, X. 2019. Extraction and antioxidant activity of Ganoderma lucidum polysaccharides using electrolyzed oxidizing water. Earth Environ. Sci. 252: 022074

Yang, Z., Chen, C., Zhao, J., Xu, W., He, Y., Yang, H. and Zhou, P. 2018. Hypoglycemic mechanism of a novel proteoglycan, extracted from Ganoderma lucidum, in hepatocytes. Eur. J. Pharmacol . 820: 77-85.

Zhao, G.R., Xiang, Z.J., Ye, T.X., Yuan, Y.J. and Guo, Z.X. 2006. Antioxidant activities of Salvia miltiorrhiza and Panax notoginseng. Food Chem. 99: 767-774

Zheng, D.S. and Chen, L.S. 2017. Triterpenoids from Ganoderma lucidum inhibit the activation of EBV antigens as telomerase inhibitors. Exp.Ther .Med. $14(4): 3273-3278$. 